Article

\title{
Shape Memory Polymer Composite Actuator: Modeling Approach for Preliminary Design and Validation
}

\author{
Salvatore Ameduri ${ }^{1, *}$, Monica Ciminello ${ }^{1}$, Antonio Concilio ${ }^{1}\left(\mathbb{D}\right.$, , Fabrizio Quadrini ${ }^{2}$ and \\ Loredana Santo ${ }^{2}$ (D) \\ 1 Department of Adaptive Structures, Centro Italiano Ricerche Aerospaziali; 81043 Capua (CE), Italy \\ 2 Department of Industrial Engineering, University of Rome Tor Vergata, via del Politecnico 1, \\ 00133 Rome, Italy \\ * Correspondence: s.ameduri@cira.it; Tel.: +39-0823-62-3556
}

Received: 6 May 2019; Accepted: 21 June 2019; Published: 27 June 2019

\begin{abstract}
The work at hand focuses on the modeling, prototyping, and experimental functionality test of a smart actuator based on shape memory polymer technology. Particular attention is paid to the specific modeling approach, here conceived as an effective predictive scheme, quick and, at the same time, able to face those nonlinearity aspects, strictly related to the large displacements shape memory polymers usually undergo. Shape memory polymer composites (SMPCs) may play a critical role for many applications, ranging from self-repairing systems to deployable structures (e.g., solar sails, antennas) and functional subcomponents (e.g., pliers, transporters of small objects). For all these applications, it is very important to have an effective tool that may drive the designers during the preliminary definition of the main parameters of the actuation system. For the present work, a SMPC plate sample has been conceived and realized in view of aerospace applications. An external fibre optic sensor has been then fixed with special adhesive. The temperatures needed for the activation of the Shape Memory Polymer (SMP) and strain storing have been provided by a thermo-gun and complete load-unload cycles, including strain storing, have been performed. Experimental displacements and strains have been used to validate a dedicated predictive theoretical approach, suited for laminates integrated with SMP layers.
\end{abstract}

Keywords: smart actuators; shape memory polymers; fiber optic sensing; deployable systems

\section{Introduction}

Shape control technology capability has been more and more explored in the technological and scientific community because of the wide range of applications that can be envisaged. In particular, studies in the aeronautical sector have been usually correlated to morphing applications, i.e., the ambition of modifying aerodynamic surfaces for attaining different behavior during the different phases of flight. Current, and for certain aspects, revolutionary approach aims at making those surfaces continuous or almost-continuous (instead of segmented, i.e., exhibiting clear points of discontinuity) and embedding all the actuators element within the structural body, so as to realize a so-called "smart structure". Within this statement, it is clear that there is no constraint to the use of a specific kind of actuators, and in fact, such architectures are realized with both the use of smart materials, like shape memory alloys (SMA), or traditional electro-magnetic motors (EMA). What is the reason why a component or the other is chosen moves from the envisaged application and the overall constraints? For instance, an industrial application would prefer consolidated actuation systems unless there are specific room or weight limitations that impose the use of less effective, less known, and less 
investigated shape memory alloys. In both the cases, however, the use of systems that have intrinsic stiffness properties and are able to generate sufficient forces to resist the high-level of loads the structures have to face during operations is necessary.

Among the many applications that can be found in the wide literature on the subject, it may be interesting to recall morphing surface systems [1-3]; automotive mechanism to control inlet/outlets opening [4], medical stents [5], and damping systems to improve a building's response to seismic events [6].

There are, however, many other applications where it may be useful to achieve different shapes without the need of developing high-force levels. This may be the case of systems that are asked to grab objects or to deploy kinematic chains without the effects of their own weight. Both these examples may refer to space systems for the capture of debris or the opening of modular antennas, or solar panels in orbit. It is a sound consequence that these kinds of elements shall be very compact and very light in order to be compliant with the demanding requisites concerning volume and weight of any component that is launched by vectors and shall stand within the specifications issued for payloads. In that case, any single added gram may make a difference. Shape memory polymers (SMP) have singular properties that well answer the needs for matching those requirements. A detailed and wide presentation of this interesting material and its applications may be found in [7]. They may exhibit a very large shape (or, equivalently, strain) recovery and do not necessitate of complex actuation systems. Their behavior is very different from SMA: shape recovery in polymers is a natural property linked to the relaxation of their long molecules as the hosting resin is softened enough (for instance, by increasing its temperature) instead of a forced phase change in a typical metal crystalline structure by an external stress or temperature field that forces its atoms to rearrange in different geometries. A shift between even very different shapes may be then achieved with very limited actuation system complexity. However, at the basis of their practical implementation, some almost hidden difficulties may constitute important showstoppers. Among them, a proper modelling and the capability to access correct information about the actual shape state are certainly important. In fact, because the phenomenon is based on the thermo-mechanical behavior of the chemical chains making the polymer, a detailed reconstruction of the complex physical laws would be, in principle, necessary. At the same time, the access to detailed and well-distributed displacement or strain data is necessary in order to properly tune those models that should be somehow simplified in order to be of some operational assistance for designers.

SMP applications are generally characterized by low energy and forces like deployable antennas [8], augmented sealing capabilities [9], or miniaturized systems for biomedical applications [10]. A small grabbing structure was realized for space cleaning operations intent, characterized by two stable configurations obtained during the memory training: a "closed-hand" and an "open hand" state. A shift between the two configurations by heating process allowed the system to grab small objects [11-13].

In the structural field, SMP interlayers were introduced to realize adaptive composite elements (SMPC). In [14], SMPC were produced by inserting a shape memory foam core between flexible composite skins; the resulting sandwich showed adaptive stiffness and geometrical properties. In [15], similarly, SMPC tubes were manufactured around a mandrel by adding a shape memory interlayer between two carbon fibre reinforced plies. In [16], another SMPC tube was manufactured with embedded flexible silicon rubber skin, augmenting load absorption capability of the structural component. In [17], SMPC were used to realize hinges of a deployable device undergoing mechanical tests to evaluate their performance. Shape recovery was shown to be a function of thermo-mechanical cycles; in detail, it was shown as the internal material re-arrangement following the continuous morphing action tended to improve process stability and bending capability. In a very extensive overview [18], many works about SMPC elements design are reported, with a special focus on aerospace applications. Low eight and low costs of those devices were emphasized, recalling proof of concept designs. However, cited applications still seemed far from actual applications because of issues still open, like limited availability, necessity of high activation temperatures, and difficult 
manufacturability. Finally, SMP composites were used in [19] to realize a morphing wing made of three different actuator architectures employing SMP and respectively using carbon-fiber (CF-SMP), SMA-wires (SMA-wire-SMP), and elastic steel-slices (ESS-SMP). The latter systems proved to offer higher recovery speeds than the former. In [20], the same authors introduced a fiber Bragg grating sensor network to monitor the morphing wing profile (shape sensing) and measure the strain actuation.

Some papers are devoted to model their mechanical behavior in order to properly address fast prototyping and design issues. In [21], the authors propose a viscoelastic rheological model, further expanded to take into account nonlinear effects [22,23]. In [24], experimental results are reproduced through a linear numerical scheme implementing a 3-element standard solid, and assuming a direct relationship between viscosity and temperature. In [25], experimental results confirm that a simplified thermo-elastic model which assumes uniform stress distributions is able to preliminarily get basic tension and deformation field evolutions. Comparison with experimental results did however show how that assumption was barely consistent. In further publications [26], that model was then systematically expanded, taking into account other configurations moving to uniform strain. Some further model extensions were also proposed, as in [27,28]. In [29], the authors developed a two-phase purely elastic model and implemented it in a finite element code with encouraging results. In this framework, recent papers addressing the modeling of the mechanical behavior of multilayered SMP devices should be also recalled, such as $[30,31]$.

The presented work focuses on these peculiar aspects of SMP-based technology. A symmetric laminate bending actuator is taken as a reference, made of an active shape memory polymer central ply and two identical carbon fibre layers on the top and the bottom of the stack, ensuring an adequate rigidity. Suited on the specific device, an original simplified predictive model was developed to describe its evolution at the different phases of typical load-unload and strain recovery cycles. It has been proven to give useful hints during the pre-design phase, allowing for a quick preliminary identification of crucial project parameters. A functionality test has been in fact organized to appreciate its ability to catch the fundamental behavior of the actuator in the case of very large displacement occurrence. The test campaign used fibre optic integrated sensors for minimal intrusiveness, minimal weight, and accurate local strain acquisition, laying the bases for deeper and more extensive optical strain gauges network implementation. The herein introduced innovative approach combines conventional laminate constitutive laws (used to describe the structural system behavior) to a non-linear load-displacement scheme (used to predict typical large deflections of a SMP system during operations). The implemented numerical solution is very quick, addressing basic iterative approaches (like bi-section or secant methods). In the end, the attention is paid to the main limitations of the proposed method and particularly to its current restriction to describe only full activated and non-activated configurations (i.e., starting and final states) when intermediate phases do not coexist.

\section{Materials and Manufacturing Methodology}

SMPC samples have a sandwich structure where the external skins made of woven carbon fabrics are separated by a shape memory interlayer made of epoxy resin. For manufacturing, commercial woven fabric prepregs were used (HexPly ${ }^{\circledR}$ M49/42\%/200T2 $\times 2 / C H S-3 K$, Stamford, CT, USA) with epoxy resin matrix. The prepreg matrix content was $42 \mathrm{wt} \%$ whereas the fabric consisted of $3 \mathrm{~K}$ high strength carbon fiber strands in a 200T2X2 arrangement [12].

Commercial prepregs typically show weak shape memory properties after cure and, for this reason, a SMP interlayer was added in the composite laminate by using a different commercial epoxy resin (3M Scotchkote $206 \mathrm{~N}$ ). This epoxy resin is in the form of a green, heat curable, thermosetting powder. SMPs increase maximum allowable strain during the memory step and durability in multiple memory-recovery steps. From a technical point of view, using SMPCs without SMP interlayer would lead to sudden ruptures and low formability in the memory step.

The materials used for the molding task are illustrated in Figure 1a. As cylindrical composite samples were manufactured, an aluminum mandrel was used to give the internal shape to the samples. 
In order to simplify part extraction after molding, a release film with $60 \mathrm{~mm}$ width was initially put on the mandrel. Subsequently, the first prepreg skin was wound on it. At this point, the SM epoxy powder was poured on the skin and, due to the prepreg tackiness, remained deposited. Subsequently, the second prepreg skin was wound, and an additional release film was applied. In order to provide the consolidation pressure during the cure in oven, uncured SMPC samples were put into a large diameter thermo-shrinkable tube (x-linked polyethylene by Elcon Megarad, Italy). The cure was performed in oven, in air, and in absence of vacuum. Due to heating at $150{ }^{\circ} \mathrm{C}$ for $15 \mathrm{~min}$, the $\mathrm{x}$-linked tube restricted and applied the necessary consolidation pressure to the composite sandwich where composite prepregs and SM interlayer cured contemporarily. After cure, samples were left to cool in air before part extraction. Cylindrical samples were manufactured and subsequently flattened, as shown in Figure 1b. It was possible to flatten the SMPC cylinder before or after its opening. For the aim of this study, an open cylinder was chosen with the final thickness of about $1 \mathrm{~mm}$. In order to open this coupon, the cylindrical sample was cut along one generatrix. The memory stage was performed by heating with a hot air gun and deforming with a cylindrical tool over a cold metal support.

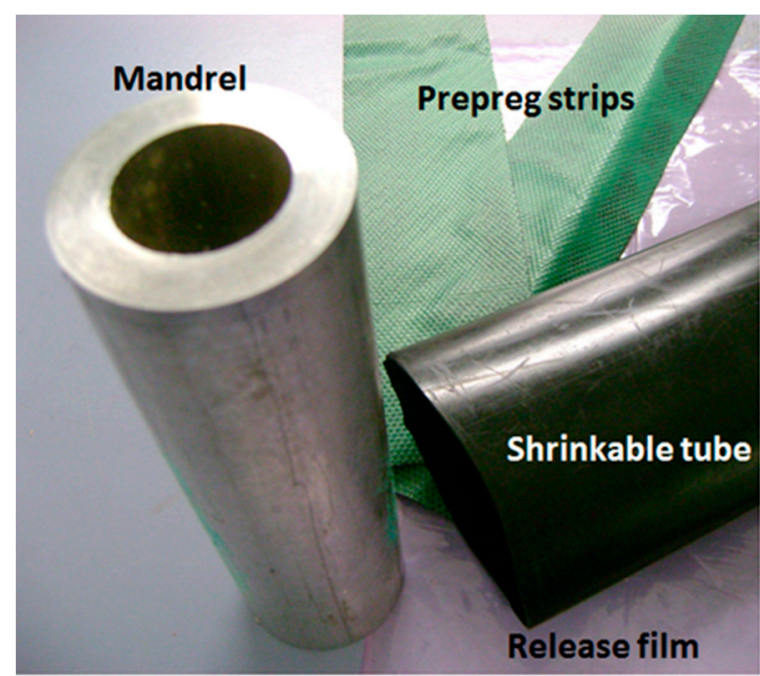

(a)

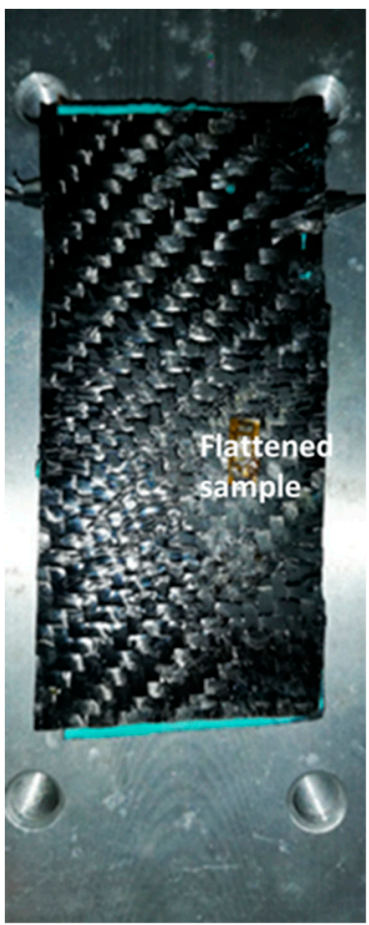

(b)

Figure 1. Elements for lab-scale manufacturing (a), and resulting Shape memory polymer composites (SMPC) parts (b).

\section{Actuator Prototype Modeling}

The present section focuses on the modeling of the SMP actuator. The following assumptions are at the basis of the theoretical scheme hereafter presented:

- although large displacements are admitted and modeled, the stress-strain curve of the materials, at fixed temperature, is linear; a consequence of the large displacement assumption is a different load distribution, depending on the current deformed shape of the sample

- $\quad$ no sliding among the laminas is considered during the entire process; this leads to a classical modality of absorption of the loads, described by the laminate constitutive laws

- the specific state points of the process refer to temperature far enough to the transition range; this means that the present scheme does not describe temperature intermediate situations (during phase change) but provides estimates in fully activated and non-activated conditions 


\subsection{Modeling Approach}

The system can be seen as a symmetric laminate made of a central ply of shape memory polymer (3M Scotchkote $206 \mathrm{~N}$ ) and two pre-preg fabric carbon fiber plies (HexPly ${ }^{\circledR}$ M49/42\%/200T2X2/CHS-3K, Stamford, USA) at 0 deg with respect the global reference system, respectively on the top and on the bottom in the stack sequence (see Figure 2).

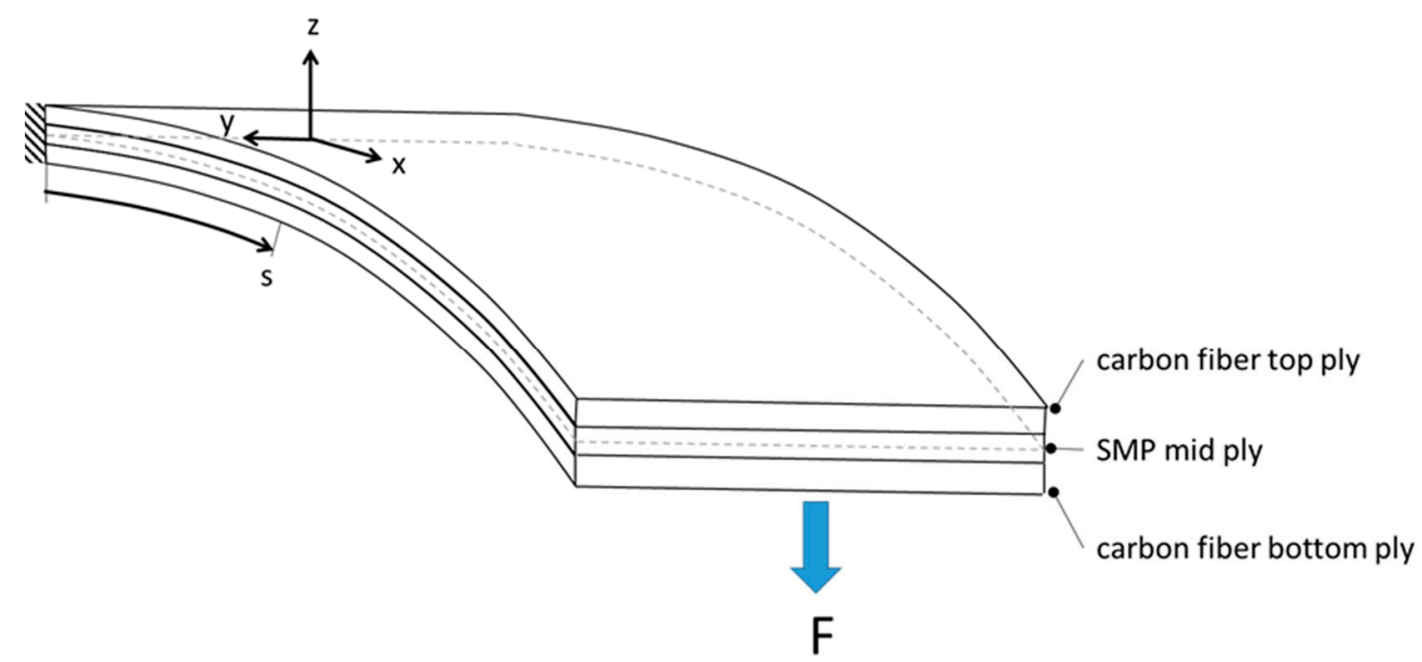

Figure 2. Scheme of the laminate.

Due to the symmetry, the coupling matrix, $\underset{B}{=}$, in the laminate constitutive equation is null and the axial and bending sets of equations can be solved separately, in the mid plane, $\underline{\varepsilon_{0}}$, and curvature, $\underline{\kappa}$ vectors:

$$
\begin{gathered}
\stackrel{A}{=}\left(\underline{\varepsilon_{0}}-\underline{\alpha}\left(T-T_{0}\right)\right)=\underline{N} \\
\underline{D} \cdot \underline{\mathcal{K}}=\underline{M}
\end{gathered}
$$

Another advantage of the symmetry is the possibility of considering the thermal distortion effects $\left(\underline{\alpha}\left(T-T_{0}\right)\right)$ only for the axial set. Since the present case deals with a bending cantilever actuator under a transversal force on the tip, attention is firstly paid on the second set of equations and the scope of the model is essentially to predict the value of the vector $\underline{\underline{\kappa}}$ of the curvature components on the $\mathrm{x}-\mathrm{y}$ plane.

$$
\underline{\kappa}=\left[\begin{array}{c}
\kappa_{x} \\
\kappa_{y} \\
\kappa_{x y}
\end{array}\right]
$$

for the different working phases of the actuator, each characterized by specific values of the stiffness matrix $\underset{D}{D}$ and of the bending moment, $\underline{M}$. This last vector, due to the just-mentioned specific working modality (that is to say, under a transversal load acting in $\mathrm{z}$ direction), assumes, for small and large displacements, the forms

$$
\begin{gathered}
\underline{M}=F\left[\begin{array}{l}
1 \\
0 \\
0
\end{array}\right] \cdot(L-s) \\
\underline{M}=F\left[\begin{array}{l}
1 \\
0 \\
0
\end{array}\right] \cdot \int_{s}^{L} \cos \vartheta(s) d s
\end{gathered}
$$


being $\mathrm{L}, \mathrm{s}$, and $\vartheta$, the actuator length, the curvilinear abscissa, and the slope along x. In Equation (4) the distance between the force and the generic station $\mathrm{s}$ is considered constant during the entire deflection; this, as it will be demonstrated in the session dedicated to the results, leads to an overestimate of the displacement. On the contrary, in Equation (5) the effect of the deflection on the distance from the force is taken into account. This phenomenon is illustrated in the scheme of Figure 3.

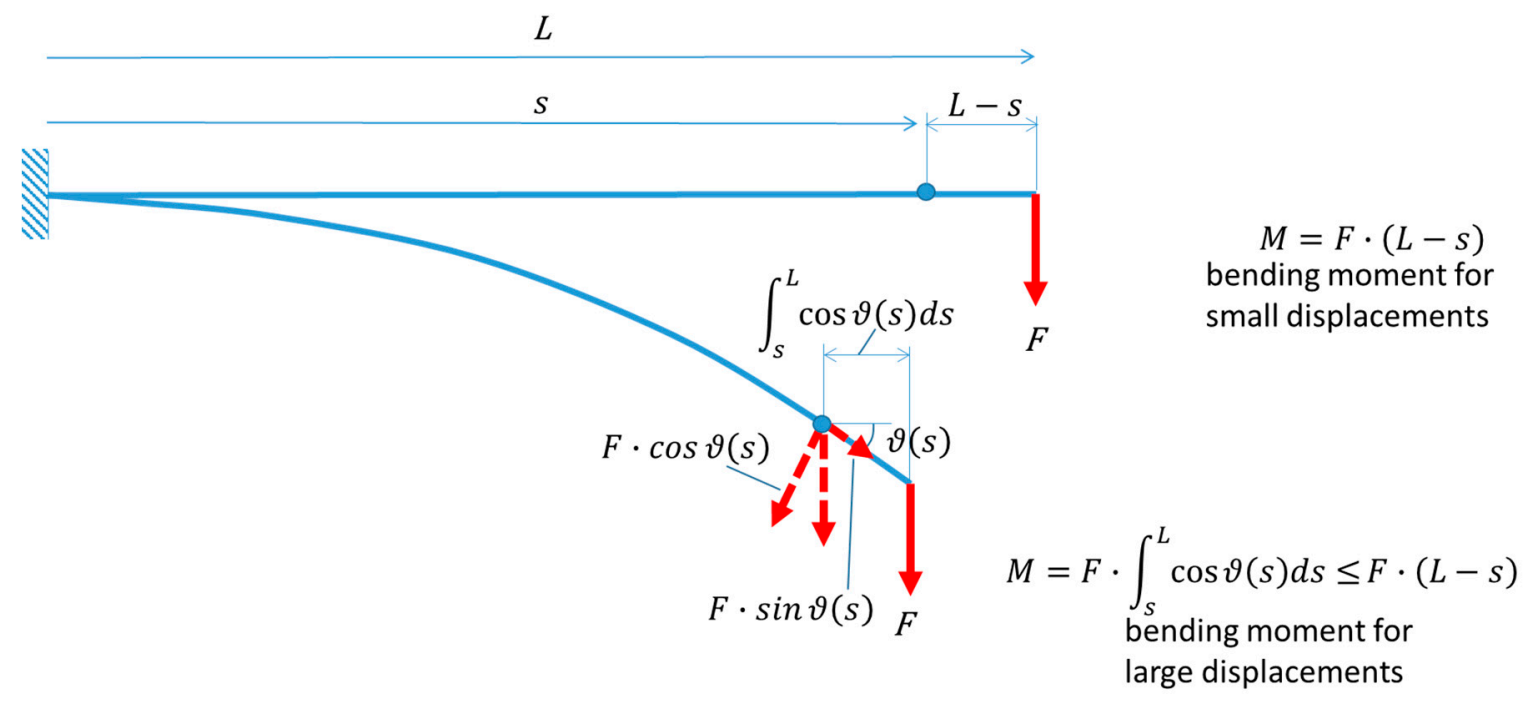

Figure 3. Effect of the large displacement on the load distribution.

The thermomechanical process simulated in this session and experimentally reproduced in the next one is schematically represented in Figure 4, in the stress-strain plane.

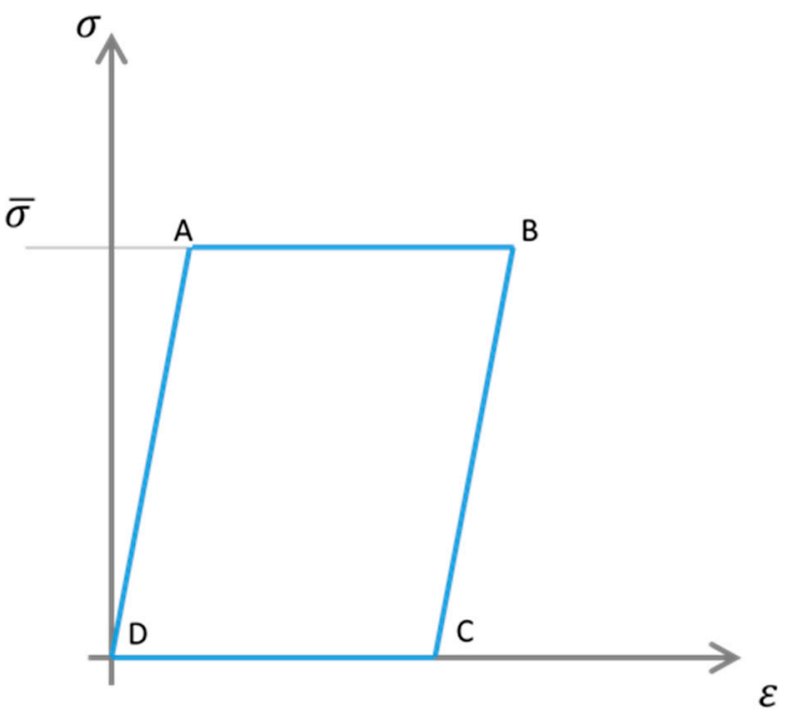

Figure 4. Scheme of the thermomechanical process simulated.

The process is quasi static and starts at $25^{\circ} \mathrm{C}$ at which the SMP is in glassy phase. The applied mechanical load causes an internal stress, $\bar{\sigma}$, and the system passes from the point (D) to the point (A). Then the system is heated up to finalise the complete phase transformation in rubbery state, arriving at B. The stress level remains in principle constant (if the effects related to the large displacements are neglected) and the deformation increases, because of the lower rigidity of the rubbery phase. If the system is cooled again and the load removed (segment B-C of the process) only a mechanical-elastic recovery is possible, while a residual deformation stored between A and B remains. Thus, to come 
back to the initial configuration (D), the temperature of the system must be increased again, enabling the shape memory effect. It is worth noting that, strictly speaking, the connections between the points of the process are not necessarily linear, due to possible nonlinearity related to the materials and to the magnitude of the displacement field. Moreover, the graphs describe only the mechanical parts of the process, while the evolution of the temperature is commented on in the following part of the session.

What qualitatively described occurs at each infinitesimal layer of the laminate. In the following, a particularization of Equation (2) is presented for each segment of the process described above. The terms $I_{s m p}$ and $I_{c f}$ used in the next part of this section represent the inertia movement of the mid-ply of SMP and of the top and bottom plies of carbon fiber:

$$
\begin{gathered}
I_{s m p}=b \int_{-\frac{t_{s m p}}{2}}^{\frac{t_{s m p}}{2}} z^{2} d z \\
I_{c f}=2 b \int_{\frac{t_{s m p}}{2}}^{\frac{t_{s m p}}{2}+t_{c f}} z^{2} d z
\end{gathered}
$$

with $b$ being the width of the laminate, $t_{s m p}$ and $t_{c f}$ the thickness of the SMP and carbon fibre plies, respectively. The factor of 2 on the right hand of (7) takes into account the symmetric contribution of both the carbon fibre plies. The same subscripts smp and ${ }_{c f}$ are used to denote the elastic tensors (Y capital letters), with the addition of the letters $l$ and ${ }_{h}$, to indicate the low temperature $\left(25^{\circ} \mathrm{C}\right)$ and high temperature $\left(120^{\circ} \mathrm{C}\right)$ phases. In the tract $\mathrm{D}-\mathrm{A}$, the laminate is at low temperature, thus Equation (2) becomes

$$
\left(\underline{I_{s m p}} \underline{\underline{Y_{s m p, l}}}+I_{c f} \underline{\underline{Y_{c f, l}}}\right) \cdot \underline{\underline{\kappa_{A, i}}}=\underline{M_{i}}
$$

Note that the subscript ${ }_{i}$ has been used to indicate the generic station along $\mathrm{x}$. Moreover, each tensor, due to the isotropic and orthotropic nature of the materials, assumes the form

$$
\underline{Y}=\left[\begin{array}{ccc}
\frac{E_{1}}{1-v_{12} v_{21}} & \frac{v_{12} E_{1}}{1-v_{12} v_{21}} & 0 \\
\frac{v_{12} E_{1}}{1-v_{12} v_{21}} & \frac{E_{2}}{1-v_{12} v_{21}} & 0 \\
0 & 0 & G_{12}
\end{array}\right]
$$

where the subscript ${ }_{1}$ and ${ }_{2}$ denote the two in-plane directions of the local frames of each ply and $E, G$, and $v$ denote the Young and shear moduli and the Poisson ratio. Solving Equation (8) at each station gives the local curvature at the point $\mathrm{A}$ of the process. The same equation, but with the mechanical tensors referring to the high temperature, may be rewritten to also estimate the condition in B:

$$
\left(I_{s m p} \underline{\underline{Y_{s m p, h}}}+I_{c f} \underline{\underline{Y_{c f, h}}}\right) \cdot \underline{\kappa_{B, i}}=\underline{M_{i}}
$$

At this point, however, a further estimate must be performed to take into account the shape memory nature of the actuator. The stored deformation-curvature, $\underline{\kappa}, i, i_{i}$ in fact may be expressed as difference between the corresponding values at points $\mathrm{A}$ and $\mathrm{B}$ :

$$
\underline{\kappa_{s, i}}=\left[\left(I_{s m p} \underline{\underline{Y_{s m p, h}}}+I_{c f} \underline{\underline{Y_{c f, h}}}\right)^{-1}-\left(I_{s m p} \underline{\underline{Y_{s m p, l}}}+I_{c f} \underline{\underline{Y_{c f, l}}}\right)^{-1}\right] \cdot \underline{M_{i}}
$$


Then the unload process begins (C-D): the external load is removed, and the system recovers the elastic part of the deformation at the lower temperature. This means that the curvature at point $C$ may be derived by the value in $\mathrm{B}$ :

$$
\underline{\kappa_{C, i}}=\underline{\kappa_{B, i}}-\left(I_{s m p} \underline{\underline{Y_{s m p, l}}}+I_{c f} \underline{\underline{\underline{Y_{c f, l}}}}\right)^{-1} \cdot \underline{M_{i}}
$$

Finally, in absence of external load, the cycle ends with again heating the system and imposing the recovery of the stored deformation-curvature, $\kappa_{s, i}$

$$
\underline{\kappa_{D, i}}=\underline{\kappa_{C, i}}-\underline{\kappa_{s, i}}
$$

After having described the stress-strain conditions of the process, the nonlinear approach adopted for computing the bending moment in case of large displacements is illustrated.

The specific bending moment considered for the application (only the first component of the vector) and the nature of the materials considered (see Equation (9)) allows to separately compute the first component of the curvature, $\kappa_{x}$, handling the first and second lines of the matrix $D$ :

$$
\left[\begin{array}{cc}
D_{11} & D_{12} \\
D_{12} & D_{22}
\end{array}\right] \cdot\left[\begin{array}{c}
\kappa_{x} \\
\kappa_{y}
\end{array}\right]=F\left[\begin{array}{l}
1 \\
0
\end{array}\right] \cdot \int_{s}^{L} \cos \vartheta(s) d s
$$

one obtains a unique equation for $\kappa_{x}$

$$
\left(D_{11}-\frac{D_{12}{ }^{2}}{D_{22}}\right) \kappa_{x}=\left(D_{11}-\frac{D_{12}^{2}}{D_{22}}\right) \frac{d \vartheta}{d s}=F \int_{s}^{L} \cos \vartheta(s) d s
$$

The relation above is a nonlinear integro-differential equation and has been solved through the iterative bisection method. By derivation it becomes

$$
\frac{d^{2} \vartheta}{d s^{2}}=\frac{F}{\left(D_{11}-\frac{D_{12}{ }^{2}}{D_{22}}\right)} \cos \vartheta(s)
$$

with the boundary conditions

$$
\vartheta(0)=0 \text { (clamped condition at the root) }
$$

and

$$
\left.\frac{d \vartheta}{d s}\right|_{L}=0 \text { (null bending moment on the tip) }
$$

The bisection method has been implemented by assuming, as trial parameter, the curvature $\frac{d \vartheta}{d s}$ on the root and having as cost function the minimization of the curvature on the tip, to meet the condition (18).

After having described the approach used for the estimate of the curvature, the mid plane deformation has been found out, solving Equation (1). In this case, the unknown, $\underline{\varepsilon}_{0}$, and the normal stress, $\underline{N}$, for small and large displacements, assume the form

$$
\underline{\varepsilon_{0}}=\left[\begin{array}{c}
\varepsilon_{x} \\
\varepsilon_{y} \\
\varepsilon_{x y}
\end{array}\right]
$$




$$
\begin{gathered}
\underline{N}=\left[\begin{array}{l}
0 \\
0 \\
0
\end{array}\right] \text { (small displacements) } \\
\underline{N}=F\left[\begin{array}{l}
1 \\
0 \\
0
\end{array}\right] \sin \vartheta(s) \text { (large displacements) }
\end{gathered}
$$

This last relation takes into account the projection $(\sin \vartheta(s))$ of the applied loads on the local axis of the deformed system. This component is represented in Figure 3 by a dashed line along the local axis of the sample. Following the same approach used for the bending, the mid-plane deformations at points $\mathrm{A}, \mathrm{B}, \mathrm{C}$, and $\mathrm{D}$, and those stored during the process are given by

$$
\begin{aligned}
& \left(A_{s m p} \underline{\underline{Y_{s m p, l}}}+A_{c f} \underline{\underline{Y_{c f, l}}}\right) \cdot \underline{\varepsilon_{0, A, i}}-\left(A_{s m p} \underline{\alpha_{s m p, l}}+A_{c f} \underline{\alpha_{c f, l}}\right)\left(T_{l}-T_{0}\right)=\underline{N_{i}} \\
& \left(A_{s m p} \underline{\underline{Y_{s m p, h}}}+A_{c f} \underline{\underline{Y_{c f, h}}}\right) \cdot \underline{\underline{\varepsilon_{0, B, i}}}-\left(A_{s m p} \underline{\alpha_{s m p, h}}+A_{c f} \underline{\alpha_{c f, h}}\right)\left(T_{h}-T_{0}\right)=\underline{N_{i}} \\
& \underline{\varepsilon_{0, C, i}}=\underline{\varepsilon_{0, B, i}}-\left(A_{s m p} \underline{\underline{Y_{s m p, l}}}+A_{c f} \underline{\underline{Y_{c f, l} l}}\right)^{-1} \cdot\left[\underline{N_{i}}+\left(A_{s m p} \underline{\alpha_{s m p, l}}+A_{c f} \underline{\alpha_{c f, l}}\right)\left(T_{l}-T_{0}\right)\right] \\
& \underline{\varepsilon_{0, D, i}}=\underline{\varepsilon_{0, C, i}}-\underline{\varepsilon_{0, s, i}} \\
& \underline{\varepsilon_{s, i}}=\left[\left(A_{s m p} \underline{\underline{Y_{s m p, h}}}+A_{c f} \underline{\underline{Y_{c f, h}}}\right)^{-1}-\left(A_{s m p} \underline{\underline{Y_{s m p, l}}}+A_{c f} \underline{\underline{Y_{c f, l}}}\right)^{-1}\right] \cdot \underline{N_{i}} \\
& +\left(A_{s m p} \underline{\underline{Y_{s m p, h}}}+A_{c f} Y_{c f, h}\right)^{-1} \cdot\left(A_{s m p} \underline{\alpha_{s m p, h}}+A_{c f} \underline{\alpha_{c f, h}}\right)\left(T_{h}-T_{0}\right) \\
& -\left(A_{s m p} Y_{s m p, l}+A_{c f} \underline{\underline{Y_{c f, l}}}\right)^{-1} \cdot\left(A_{s m p} \underline{\alpha_{s m p, l}}+A_{c f} \underline{\alpha_{c f, l}}\right)\left(T_{l}-T_{0}\right)
\end{aligned}
$$

The above-mentioned cross section areas, $A_{s m p}$ and $A_{c f}$, are defined as follows

$$
A_{s m p}=b \int_{-\frac{t_{s m p}}{2}}^{\frac{t_{s m p}}{2}} d z
$$

and

$$
A_{c f}=2 b \int_{\frac{t_{\text {sm }}}{2}}^{\frac{t_{s m p}}{2}+t_{c f}} d z
$$

With specific reference to the large displacement field, as already done for the bending, the first component of the mid-plane deformation may be computed separately:

$$
\left(A_{11}-\frac{A_{12}^{2}}{A_{22}}\right) \varepsilon_{0 x}=F \sin \vartheta+\left(\alpha_{x}-\frac{A_{12}}{A_{22}} \alpha_{y}\right)\left(T-T_{0}\right)
$$

\subsection{Simulation Results}

The approach described above was used to predict the deflection of the laminate and related strain field. In Table 1, the parameters considered in the analysis are summarized. 
Table 1. Simulation parameters.

\begin{tabular}{ccc}
\hline Parameter & Description & Value \\
\hline$E_{c f, 1, l}(\mathrm{GPa})$ & $\begin{array}{l}\text { Young modulus of carbon fabric ply along } 1 \text { direction in the } \\
\text { ply reference coordinate frame, at low temperature }\left(25^{\circ} \mathrm{C}\right)\end{array}$ & 52 \\
& $\begin{array}{c}\text { Young modulus of carbon fabric ply along 2 direction in the } \\
\text { ply reference coordinate frame, at low temperature }\left(25^{\circ} \mathrm{C}\right)\end{array}$ & 52 \\
$E_{c f, 2, l}(\mathrm{GPa})$ & $\begin{array}{c}\text { Young modulus of carbon fabric ply along } 1 \text { direction in the } \\
\text { ply reference coordinate frame, at high temperature }\left(120^{\circ} \mathrm{C}\right)\end{array}$ & 3.64 \\
$E_{c f, 1, h}(\mathrm{GPa})$ & Young modulus of carbon fabric ply along 2 direction in the & 3.64 \\
$E_{c f, 2, h}(\mathrm{GPa})$ & ply reference coordinate frame, at high temperature $\left(120^{\circ} \mathrm{C}\right)$ & 0.33 \\
$v_{21}$ & Poisson ration referred to directions 1 and 2 & 3.64 \\
$E_{s m p, l}(\mathrm{GPa})$ & Young modulus of the SMP, at low temperature $\left(25^{\circ} \mathrm{C}\right)$ & 0.080 \\
$E_{s m p, h}(\mathrm{GPa})$ & Young modulus of the SMP, at high temperature $\left(120^{\circ} \mathrm{C}\right)$ & 0.33 \\
$t_{c f}(\mathrm{~mm})$ & Thickness of the carbon fibre plies & 0.10 \\
$t_{s m p}(\mathrm{~mm})$ & Thickness of the SMP ply & 0.5 \\
$\alpha_{s m p, 1}$ and $\alpha_{s m p, 2}\left(\mu \varepsilon / \mathrm{C}^{\circ}\right)$ & Thermal expansion coefficients of the carbon fabric ply in the & local reference frame \\
$\alpha_{s m p}\left(1 / \mathrm{C}^{\circ}\right)$ & Thermal expansion coefficient of the SMP & 36 \\
$b(\mathrm{~mm})$ & Laminate width & 40 \\
$L(\mathrm{~mm})$ & Laminate length & 80 \\
$F(\mathrm{~N})$ & Applied force at the tip & 1.267 \\
\hline
\end{tabular}

At first, the vertical displacement of the laminate and the curvature were computed (see Figures 5 and 6), considering both the small and large displacement assumptions. The corresponding curvature distribution is reported in the next plot.

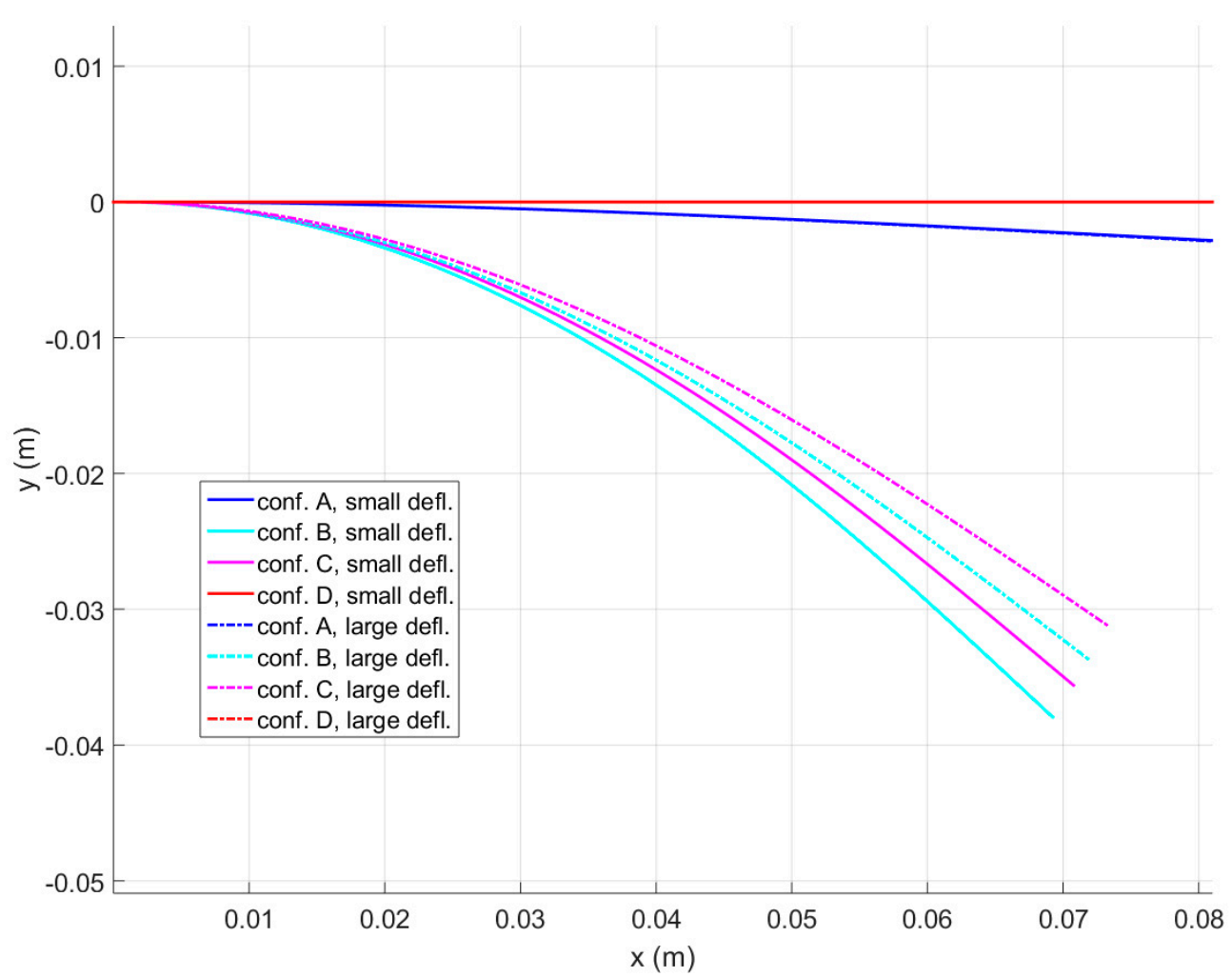

Figure 5. Vertical displacement of the laminate at the conditions A, B, C, and D of the process of Figure 4, in small and large displacement assumptions. 


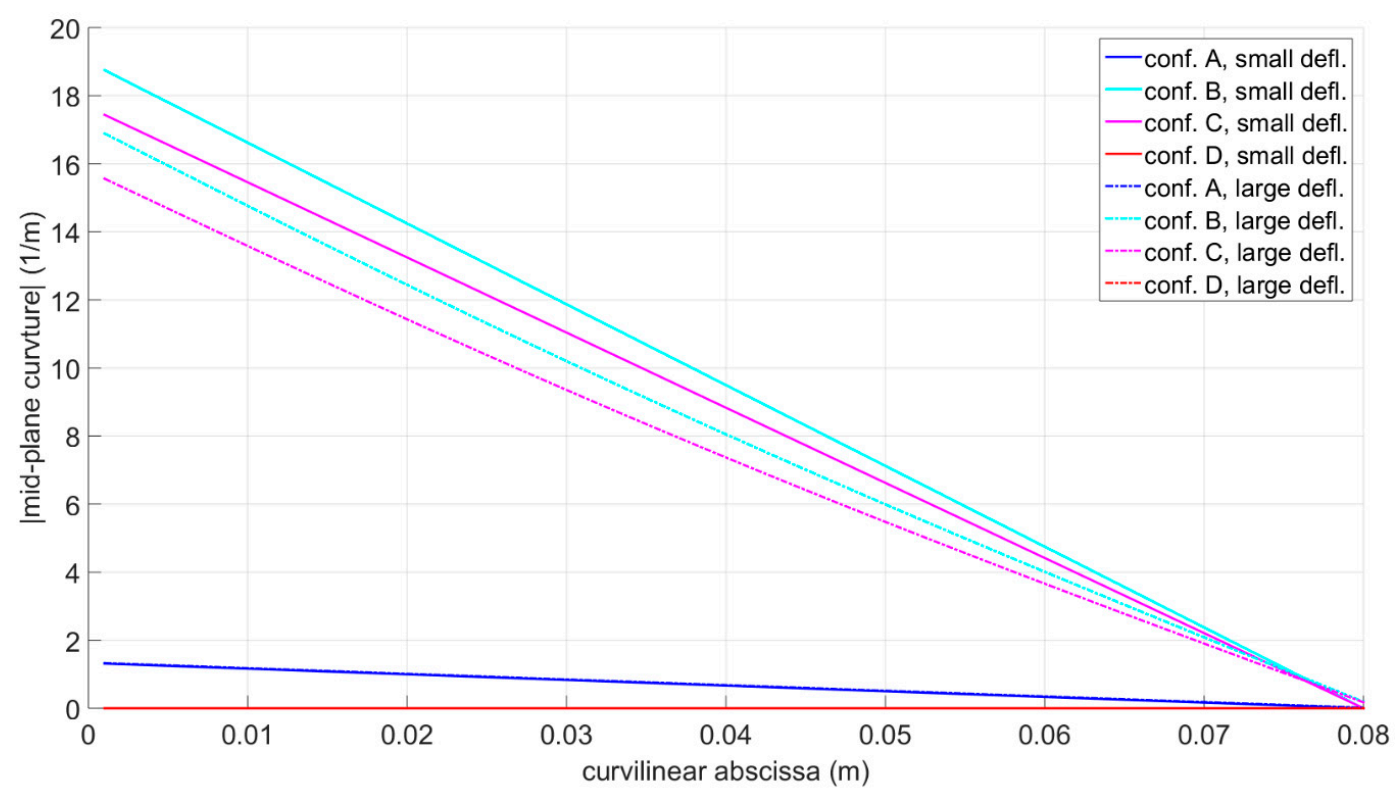

Figure 6. Curvature distribution at the conditions A, B, C, and D of the process of Figure 4, in small and large displacement assumptions.

For all the configurations, the simulations under the assumption of small displacements led to an underestimate of the vertical displacement. The higher is the displacement the wider is the deviation, since over a certain level of slope, the linear relation (4) cannot be used anymore.

Pretty linear curvature distributions were found both for large and small displacement assumptions, as shown in Figure 6. The slope of the line is clearly related to the specific bending moment, that is, 0 on the tip, and achieves the maximum level on the constraint. Also, in this case, the assumption of small displacement led to an overestimation of the parameter.

The only approach able to catch some (negligible) strain on the mid-plane is the nonlinear-large displacement one (see Figure 7). In this case, in fact, the vertical force has a component on the axis deformed sample, as already discussed in the previous sub-session (see Equation (21)).

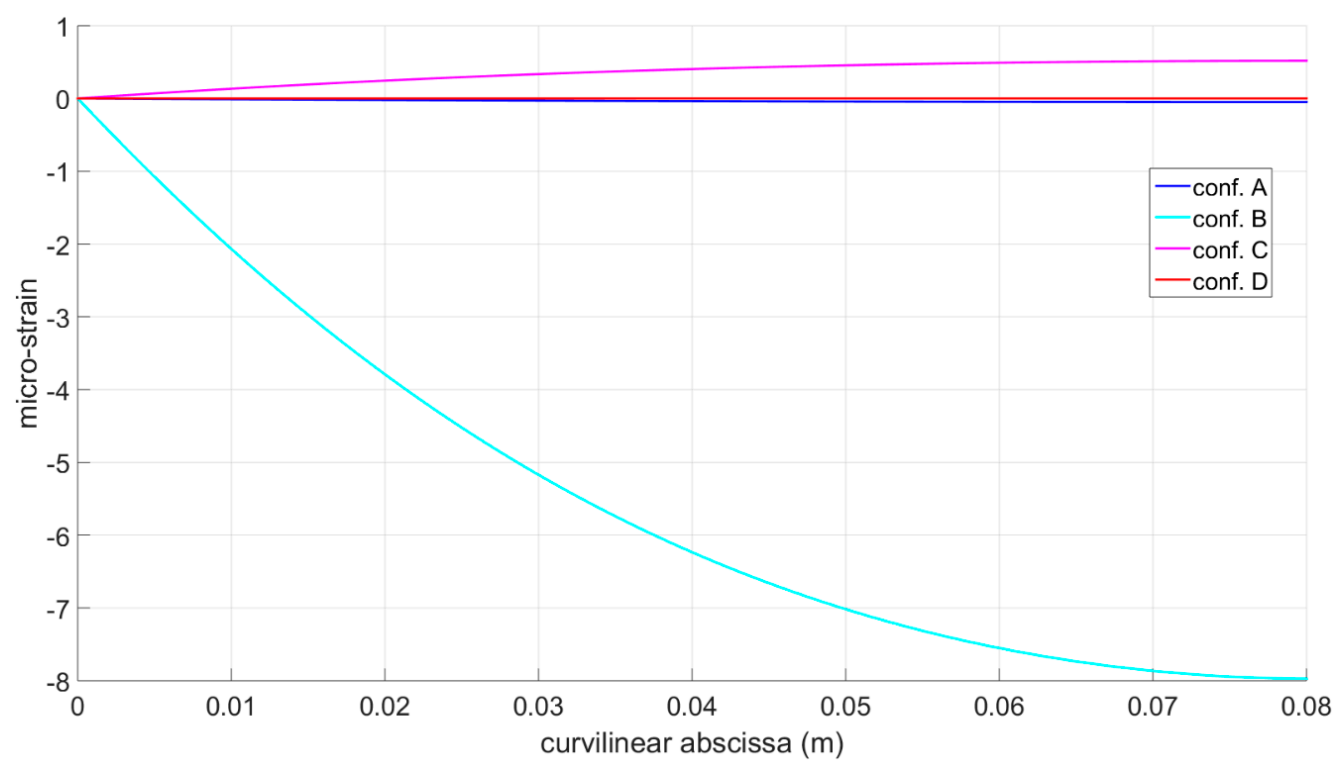

Figure 7. Mid-plane strain at the conditions A, B, C, and D of the process of Figure 4, in large displacement assumption. 
Finally, a comparison between linear and non-linear results is presented in the Table 2 to highlight the impact of the large displacement assumption on the numerical predictions.

Table 2. Linear vs. nonlinear results.

\begin{tabular}{ccccccc}
\hline & \multicolumn{3}{c}{ Tip Displacement } & \multicolumn{3}{c}{ Curvature at the Root } \\
\hline condition & Linear $(\mathrm{mm})$ & Non-linear $(\mathrm{mm})$ & Delta $(\mathrm{mm})$ & Linear $(1 / \mathrm{m})$ & Non-linear $(1 / \mathrm{m})$ & Delta $(1 / \mathrm{m})$ \\
\hline A & 2.83 & 2.88 & 0.05 & 1.31 & 1.33 & 0.02 \\
\hline B & 37.9 & 33.7 & -4.2 & 18.7 & 16.9 & -1.8 \\
\hline C & 35.5 & 31.2 & -4.3 & 17.4 & 15.5 & -1.9 \\
\hline D & 0 & 0 & 0 & 0 & 0 & 0 \\
\hline
\end{tabular}

A maximum deviation of $4.3 \mathrm{~mm}$ was found, in the condition $\mathrm{C}$, on the tip displacement, corresponding to a percentage deviation of almost $14 \%$ on the total displacement $(31.2 \mathrm{~mm})$. At the same condition, the curvature predictions also showed the max deviation: $1.9 \mathrm{~m}^{-1}$ over a total value of $16.9 \mathrm{~m}^{-1}$, that is to say, about $11 \%$.

After having simulated the deformation achieved at the different phases of the process, the effects of some design parameters were investigated. For the next analyses, and for the experimental comparison presented in the next session, only the large displacement approach was used. In Figure 8 on the top, both the storable curvature and the recoverable transversal displacement for different numbers of carbon fabric plies are plotted.

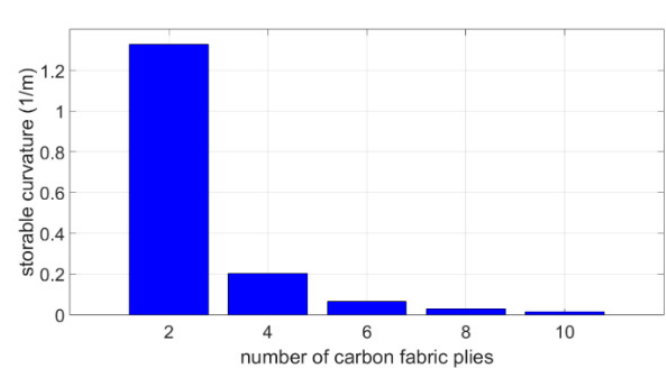

(a)

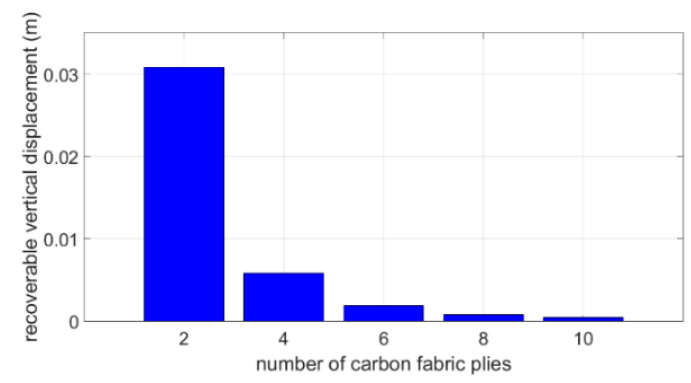

(b)

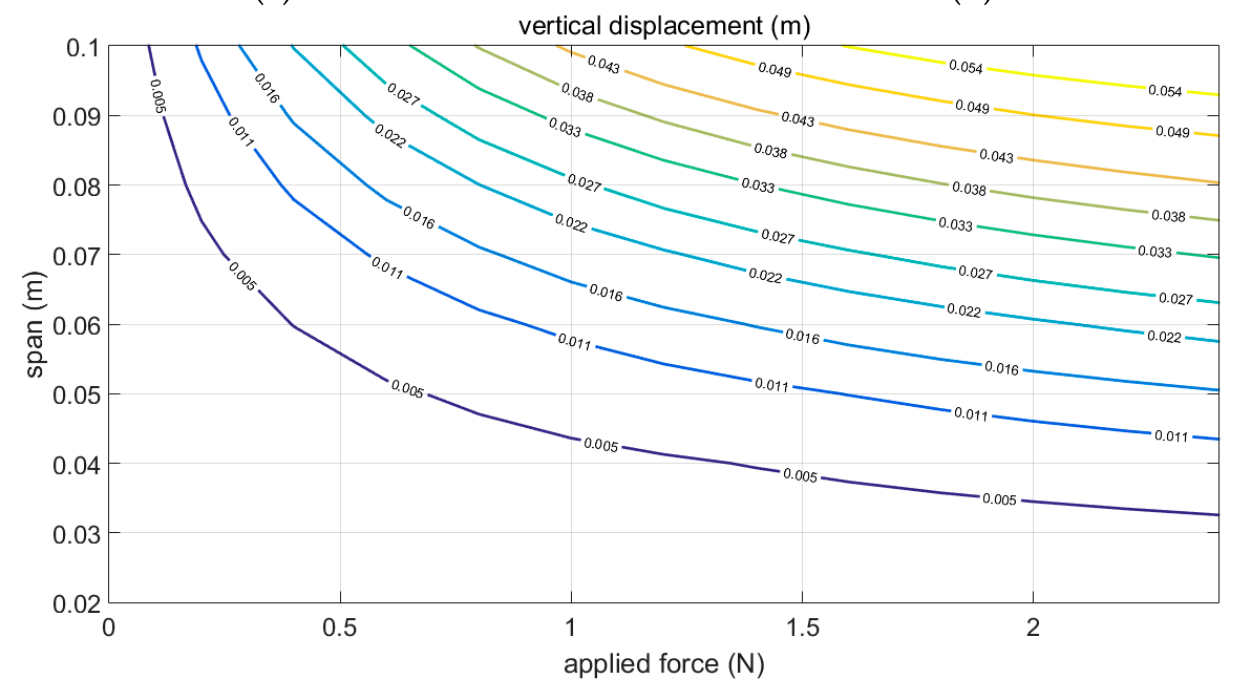

(c)

Figure 8. Storable curvature (a) and recoverable transversal displacement (b) vs. number of carbon fabric plies (against a single SMP internal layer); effect of the span, and of the applied force (c) on the transversal displacement for the basic stack configuration (i.e., two external carbon fabric plies and one SMP layer in the middle). 
The impact of this parameter appears really remarkable and can be interpreted considering that the carbon fabric authority contributes to the stiffness of the structure, limiting its flexibility and thus its capability of storing strain in the SMP layer.

Finally, the combined effect of the applied force, $F$, and of the sample span, $L$, at fixed cross section, were explored; their impact on the recoverable displacement is illustrated in the contour plot on the bottom of Figure 8, obtained for the basic stack configuration (i.e., two external carbon fabric plies and one SMP layer in the middle). The higher the force, the higher the displacement produced and thus stored; the span, on the other hand, strongly increases the flexibility and thus the deformations.

\section{Prototype Instrumentation and Validation Test}

The aim of the experimental test campaign is to monitor the shape recovery of the SMPC sample, numerically investigated in the previous section.

\subsection{Actuator Instrumentation}

In the last two decades, the use of optical fibres and related optical components has dramatically increased with the development of a large variety of fibre optic sensors with the possibility of realizing sensing technologies, which are highly competitive with respect to traditional, less expensive, electrical sensors [11,20,32]. High strain, high temperature, and continuous monitoring can be highlighted [33]. In this application, selected optic fibres are characterized by an outer diameter of $0.250 \mathrm{~mm}$ and a polyimide coating. FBG is $1 \mathrm{~cm}$ long. Fibre is bonded on the outer surface of the SMPC coupon. For long term, high strain $(\sim 1 \%)$, harsh environmental, and irregular surface, applications of two-part epoxies are required. M-Bond GA2 exhibits excellent adhesion to composite surfaces and, thanks to their high viscosity, exhibits a good filler behavior compensating surface roughness. An extra high temperature silicone layer is added to protect and seal the FBG. A second sensor is bonded providing an absolute temperature measurement to be used for off-line compensation. In order to activate the SMPC samples, a thermos gun generator was used.

A picture of the experimental setup is provided in Figure 9, on the left. The sample, with the mechanical features and the size reported in Table 1, was clamped on a vertical truss and integrated with two fiber optic sensors, to monitor the local deformation and temperature. Both the sensors were connected to the spectrum analyzer (MOI sm-130) directed by the software (Enligth). A detail of the sample instrumented with these sensors is provided in Figure 9, on the right. A digital camera was also used to capture the entire motion of the system during the cycle and to estimate its vertical displacement.

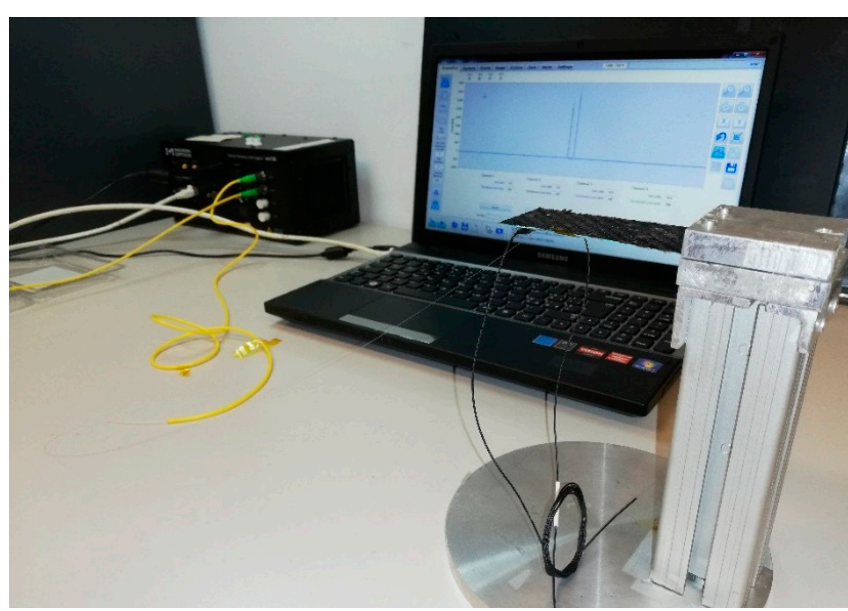

(a)

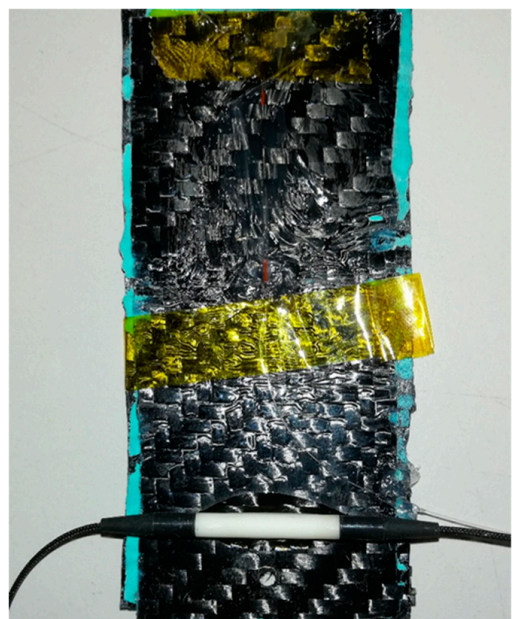

(b)

Figure 9. Experimental setup used for reproducing the SMP actuator working cycle: entire setup (a) and detail of the specimen (b). 


\subsection{Results and Validation}

The scope of the tests was to reproduce the load-unload-strain recovery cycle reported in Figure 4, with specific interest in the conditions identified by points A, B, C, and D.

The experiment was conducted through the following procedure:

- Step 1: a weighted mass was hung to the tip of the sample at room temperature, waiting for the stabilization of the configuration; the achieved deflection corresponds to the point $\mathrm{A}$ of the process Step 2: the sample was heated by a thermo-gun up to arrive at a temperature of $120^{\circ} \mathrm{C}$; a large displacement was registered when the test condition was stabilized (no further vertical displacement were observed); this condition correspond to the point $B$ of the process

- Step 3: the system was left cooling up to coming back to the environmental temperature; in this phase of the process, strain is stored for the forthcoming shape memory recovery. The geometric configuration is still represented by the point $B$, even as temperature and mechanical properties got back to the values at the beginning of the process

- Step 4: the mass is removed to allow the elastic recovery and arrive at condition C. A residual deformation is clearly present and corresponds to the strain stored in the previous step

- Step 5: the sample is heated again, up to recover the original shape (condition D)

The pictures in Figure 10 illustrate the configuration assumed by the actuator for each of the just-mentioned steps. A video of the entire process was also made (see "Supplementary Materials" section).

The experiment lasted a total of $800 \mathrm{~s}$. Both the strain close to the clamp and the temperature were acquired by the fiber optic sensors and reported in Figure 11. A dedicate compensation process was performed to distinguish the mechanical strain measurements from the thermal distortion caused by the process heating phases.

The system is at first unloaded, as shown by the initial horizontal tract, lasting about $15 \mathrm{~s}$. Then a mass is hung at the tip and the elastic deformation occurs until a stable equilibrium is achieved. This condition corresponds to the point A of the process. Note that the temperature is kept at $25^{\circ} \mathrm{C}$ during the first $15 \mathrm{~s}$ of the process, even after the achievement of the elastic equilibrium. Then the heating process starts, and the temperature arrives at a maximum value of $120^{\circ} \mathrm{C}$. Before $100{ }^{\circ} \mathrm{C}$, the system is not really affected by this increase and remains in equilibrium under the applied load. As the temperature further arises, however, the transformation is enabled in the SMP material and also the mechanical properties of the pre-preg carbon fibric change. In practice, a long fall of the deformation occurs, up to a new mechanical equilibrium (configuration B), highlighted by the wide horizontal tract of the curve, ranging from about 100 to $320 \mathrm{~s}$. During this timeframe, the system is left cooling up to arriving at about $35^{\circ} \mathrm{C}$, to recover the initial phase and to store deformation. Then the load is removed and the elastic deformation is recovered, as proved by the upwards small step of the strain (configuration C). The system now has the possibility of stabilizing, since the temperature remains constant for 10 more seconds. After this period, the last part of the process starts: the system is heated again and the shape memory effect is enabled, as evident by the sharp steepening of the curve. The temperature arrives at $130{ }^{\circ} \mathrm{C}$ but the strain recovery process is already finalized before, at $120^{\circ} \mathrm{C}$ : the deformation curve becomes horizontal and stays that way during the entire cooling process. The just mentioned load-unload and heating-cooling phases have been highlighted in both the plots of Figure 11. 


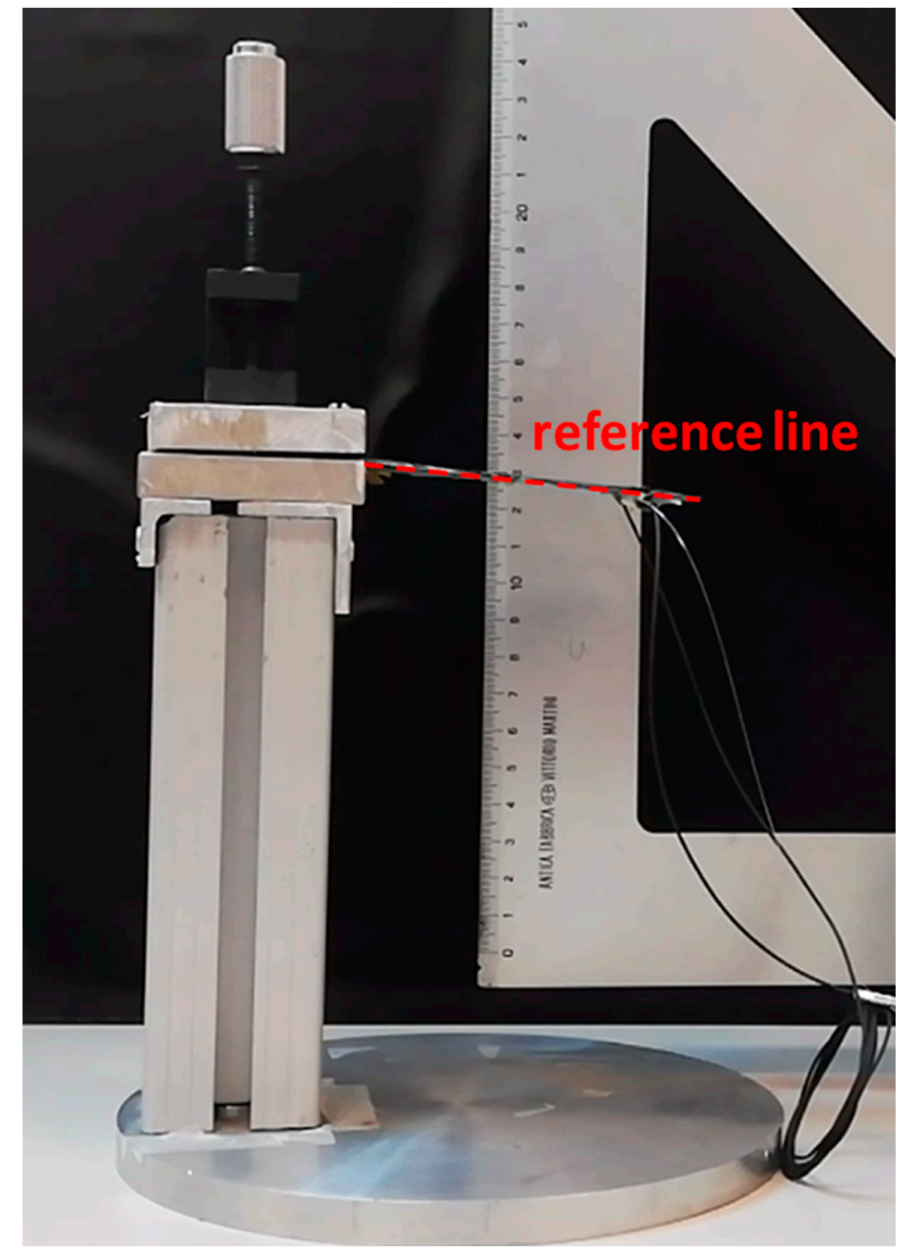

(a)
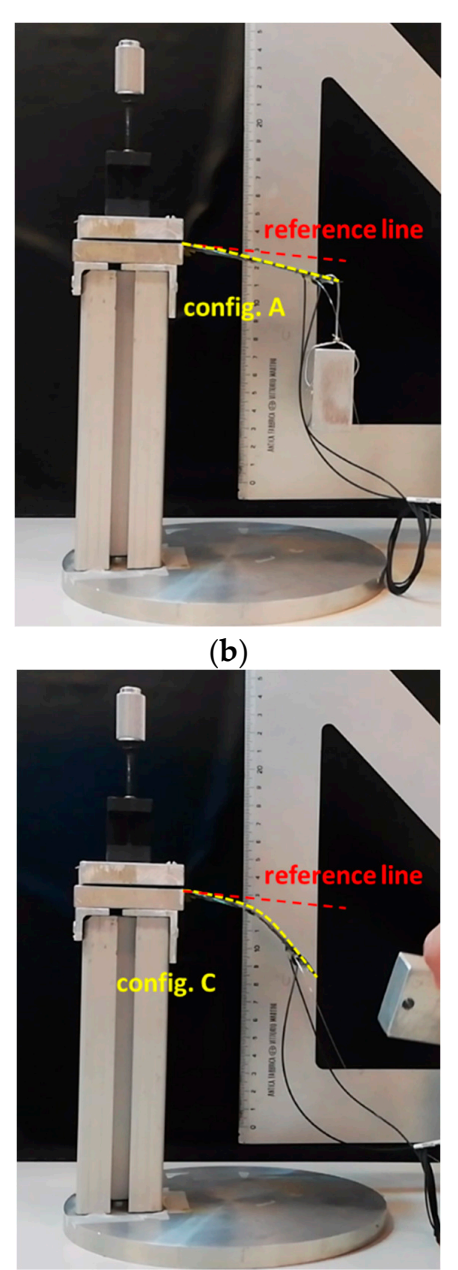

(d)
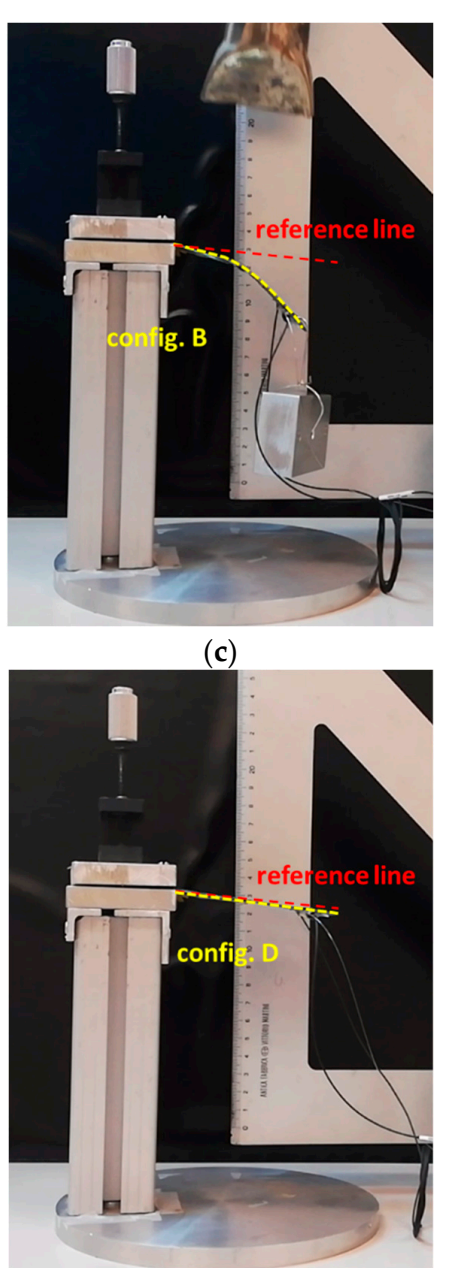

(e)

Figure 10. Different phases of the load-unload process: reference (a), loaded at low temperature (b), loaded at high temperature (c), unloaded after cooling (d), recovery (e). 


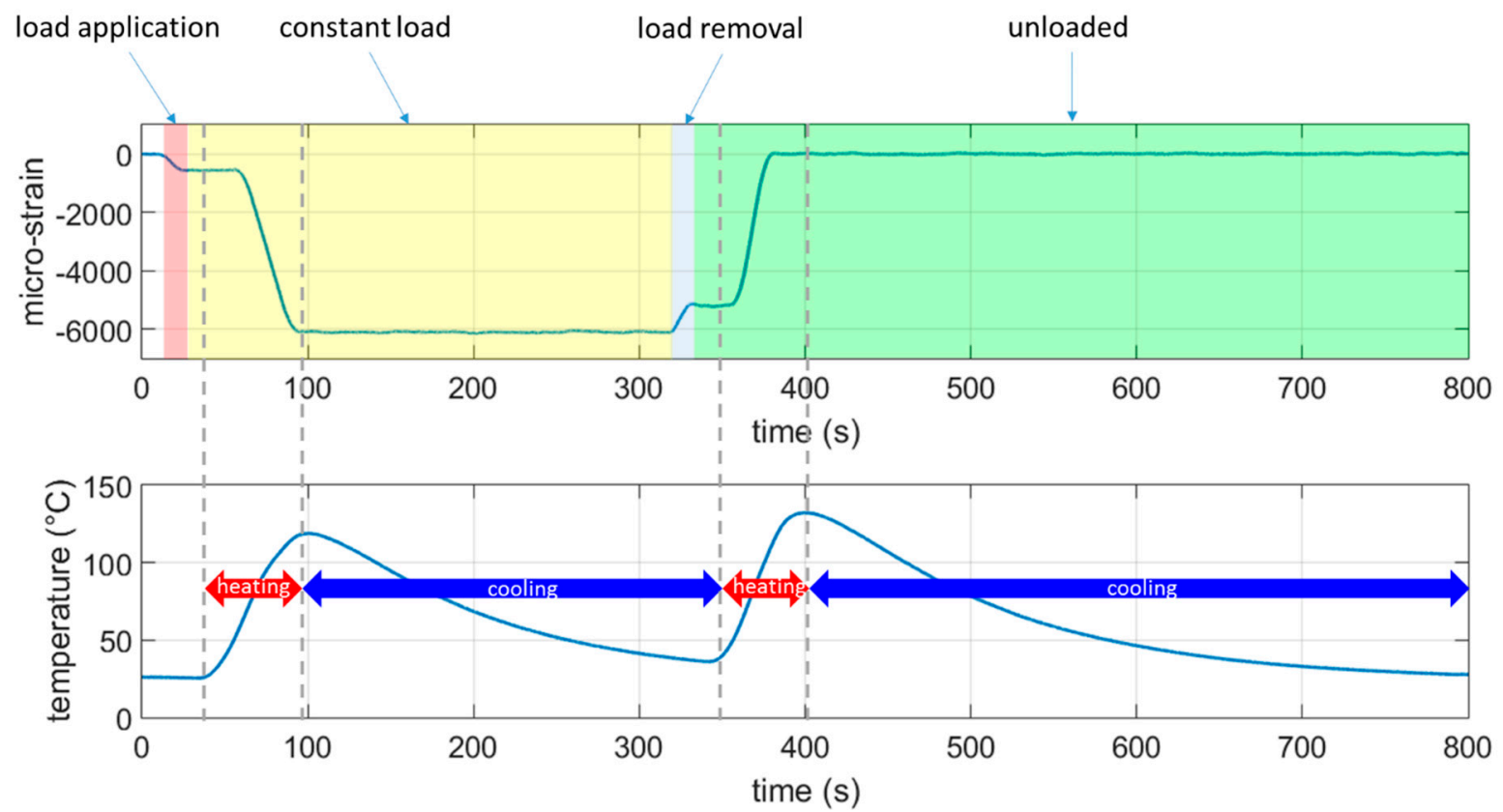

Figure 11. Strain measured close to the clamp (top) and temperature (bottom) vs. time during the entire load-unload process.

A comparison between numerical and experimental displacement and strain on the tip and at the root, respectively, is finally reported in Table 3.

Table 3. Numerical (non-linear) vs. experimental results.

\begin{tabular}{ccccccc}
\hline & \multicolumn{3}{c}{ Tip Displacement } & \multicolumn{3}{c}{ Strain Closed to the Root } \\
\hline condition & $\begin{array}{c}\text { Numerical } \\
(\mathrm{mm})\end{array}$ & $\begin{array}{c}\text { Experimental } \\
(\mathrm{mm})\end{array}$ & Delta $(\mathrm{mm})$ & $\begin{array}{c}\text { Numerical } \\
(\mu \text {-strain })\end{array}$ & $\begin{array}{c}\text { Experimental } \\
(\mu \text {-strain })\end{array}$ & $\begin{array}{c}\text { Delta } \\
(\mu \text {-strain })\end{array}$ \\
\hline A & 2.88 & 2.94 & 0.06 & -524.4 & -573 & -48.6 \\
\hline B & 33.7 & 29.2 & -4.5 & -6422 & -6133 & 289 \\
\hline C & 31.2 & 27.7 & -3.5 & -5890 & -5227 & 663 \\
\hline D & 0 & 0.69 & 0.69 & 0 & 64 & 64 \\
\hline
\end{tabular}

The maxima deviations on the displacement and on the deformation were found at the conditions $B$ and $C$, with net values of $4.5 \mathrm{~mm}$ and $663 \mu$-strain (15 and 13\%, respectively).

\section{Conclusions and Further Steps}

The motivation of the work was the definition of a quick numerical scheme that the designers can use during the definition of the main parameters of the actuator. The innovative aspect of the approach is represented by the possibility of having a quick estimate of the behavior of the system, catching nonlinear features strictly related to the large displacements, typical of this kind of application. The approach adopted for solving the model was iterative due to the intrinsic nonlinearity. However, due to the specific nature of the equations, basic iterative schemes can be adopted, with a consequent saving in terms of numerical efforts.

A dedicated test campaign highlighted a good agreement with the numerical predictions, both in terms of strain and displacements, and confirmed the possibility of using the approach for preliminary considerations.

Future work will focus on the extension of the operational range of the model, taking into account of the impact of the speed of the process and of the evolution of the state variables along the entire 
phases of the cycle (thus also within the transition phase). Finally, the impact of different constraint conditions and of more sophisticated load-unload processes will be subjected to further works, together with the extension of the model to more complex geometries (e.g., cambered or cylindrical shells).

Supplementary Materials: The following are available online at http://www.mdpi.com/2076-0825/8/3/51/s1, Video S1: "SMP working cycle".

Author Contributions: S.A. performed the formal analysis, identified the methodology, and contributed to the editing; M.C. took care of the validation and contributed to the writing; A.C. and L.S. supervised the work and contributed to the overall assessment; F.Q. dealt with the data curation and contributed in writing.

Funding: This research received no external funding.

Conflicts of Interest: The authors declare no conflict of interest.

\section{References}

1. Ameduri, S.; Concilio, A.; Pecora, R.; Karagiannis, D. A single slotted morphing flap based on SMA technology. Smart Struct. Syst. 2016, 17, 819-835. [CrossRef]

2. Dayananda, G.N.; Varughese, B.; Rao, M.S. Shape Memory Alloy Based Smart Landing Gear for an Airship. J. Aircr. 2007, 44, 1469-1477. [CrossRef]

3. Ameduri, S.; Concilio, A.; Favaloro, N.; Pellone, L. A Shape Memory Alloy Application for Compact Unmanned Aerial Vehicles. Aerospace 2016, 3, 16. [CrossRef]

4. Singh, A.; Raj Singh, J.; Kumar Verma, P. Automotive application of shape memory alloys. In Proceedings of the 15th International Conference on Recent Trends in Engineering, Applied Science and Management, Rajasthan, India, 1 April 2018.

5. Petrini, L.; Migliavacca, F. Biomedical Applications of Shape Memory Alloys. J. Metall. 2011, 2011. [CrossRef]

6. Ozbulut, O.E.; Hurlebaus, S.; Desroches, R. Seismic Response Control Using Shape Memory Alloys: A Review. J. Intell. Mater. Syst. Struct. 2011, 22, 1531-1549. [CrossRef]

7. Hager, M.D.; Bode, S.; Weber, C.; Schubert, U.S. Shape memory polymers: Past, present and future developments. Prog. Polym. Sci. 2015, 49,3-33. [CrossRef]

8. An, Y.; Kim, J.; Goo, N.S.; Kim, Y.; Park, J.K.; Yu, W.-R. Quantitative evaluation of the three-dimensional deployment behavior of a shape memory polymer antenna. Smart Mater. Struct. 2018, 27, 105007. [CrossRef]

9. Alexander, P.W.; Luntz, J.E.; Moyer, A.W.; Brei, D.; Ranga, S.; Johnson, N.L. Adjustable Panel Closure Bumpers Incorporating Shape Memory Polymers. U.S. Patent 9,290,979,B1, 22 March 2016.

10. Wong, Y.; Kong, J.; Widjaja, L.K.; Venkatraman, S.S.; Venkatraman, S. Biomedical applications of shape-memory polymers: how practically useful are they? Sci. China Ser. B Chem. 2014, 57, 476-489. [CrossRef]

11. Quadrini, F.; Santo, L.; Ciminello, M.; Concilio, A.; Volponi, R.; Spena, P. Shape memory polymeric composites sensing by optic fibre Bragg gratings: A very first approach. AIP Conf. Proc. 2016, 1736, 020090. [CrossRef]

12. Quadrini, F.; Tedde, G.M.; Santo, L. Shape memory composite hands for space applications. In Proceedings of the ASME 2015 International Manufacturing Science and Engineering Conference, Charlotte, NC, USA, 8-12 June 2015; Volume 1.

13. Santo, L.; Quadrini, F.; Squeo, E.A.; Dolce, F.; Mascetti, G.; Berolotto, D.; Villadei, W.; Ganga, P.L.; Zolesi, V. Behavior of shape memory epoxy foams in microgravity: Experimental results of STS-134 mission, Micrograv. Microgravity Sci. Technol. 2012, 24, 287-296. [CrossRef]

14. Ayranci, C.; Carey, J.P. Handbook of Advances in Braided Composite Materials; Carey, J.P., Ed.; Woodhead Publishing: Sawston, Cambridge, UK, 2017.

15. Díaz Lantada, A.; Lafont Morgado, P.; Lorenzo Yustos, H.; Lorenzo Esteban, V.; Muñoz-García, J.; Muñoz Sanz, J.L.; Echavarri Otero, J.; Muñoz Guijosa, J.M. Biodevices based on shape-memory polymers: Current capabilities and challenges. In Proceedings of the Biodevices 2009-International Conference on Biomedical Electronics and Devices, Porto, Portugal, 14-17 January 2009.

16. Chen, Y.J.; Sun, J.; Liu, Y.J.; Leng, J.S. Variable stiffness property study on shape memory polymer composite tube. Smart Mater. Struct. 2012, 21, 094021. [CrossRef]

17. Lan, X.; Liu, Y.; Lv, H.; Wang, X.; Leng, J.; Du, S. Fiber reinforced shape-memory polymer composite and its application in a deployable hinge. Smart Mater. Struct. 2009, 18, 024002. [CrossRef] 
18. Liu, Y.; Du, H.; Liu, L.; Leng, J. Shape memory polymers and their composites in aerospace applications: A review. Smart Mater. Struct. 2014, 23, 023001. [CrossRef]

19. Yu, K.; Yin, W.L.; Sun, S.H.; Liu, Y.J.; Leng, J.S. Design and analysis of morphing wing based on SMP composite. SPIE 2009, 7290, 72900S.

20. Yin, W.L.; Fu, T.; Liu, J.C.; Leng, J.S. Structural shape sensing for variable camber wing using FBG sensors. SPIE 2009, 7292, 72921H.

21. Tobushi, H.; Hashimoto, T.; Hayashi, S.; Yamada, E. Thermomechanical Constitutive Modeling in Shape Memory Polymer of Polyurethane Series. J. Intell. Mater. Syst. Struct. 1997, 8, 711-718. [CrossRef]

22. Bhattacharyya, A.; Tobushi, H. Analysis of the isothermal mechanical response of a shape memory polymer rheological model. Polym. Eng. Sci. 2000, 40, 2498-2510. [CrossRef]

23. Tobushi, H.; Okumura, K.; Hayashi, S.; Ito, N. Thermomechanical constitutive model of shape memory polymer. Mech. Mater. 2001, 33, 545-554. [CrossRef]

24. Lin, J.R.; Chen, L.W. Shape-memorized crosslinked ester-type polyurethane and its mechanical viscoelastic model. J. Appl. Polym. Sci. 1999, 73, 1305-1319. [CrossRef]

25. Liu, Y.; Gall, K.; Dunn, M.L.; Greenberg, A.R.; Diani, J. Thermomechanics of shape memory polymers: Uniaxial experiments and constitutive modeling. Int. J. Plast. 2006, 22, 279-313. [CrossRef]

26. Gilormini, P.; Diani, J. On modeling shape memory polymers as thermoelastic two-phase composite materials. Comptes Rendus Mécanique 2012, 340, 338-348. [CrossRef]

27. Diani, J.; Liu, Y.; Gall, K. Finite strain 3D thermoviscoelastic constitutive model for shape memory polymers. Polym. Eng. Sci. 2006, 46, 486-492. [CrossRef]

28. Chen, Y.-C.; Lagoudas, D.C. A constitutive theory for shape memory polymers. Part I: Large deformations. J. Mech. Phys. Solids 2008, 56, 1766-1778. [CrossRef]

29. Reese, S.; Böl, M.; Christ, D. Finite element-based multi-phase modelling of shape memory polymer stents. Comput. Methods Appl. Mech. Eng. 2010, 199, 1276-1286. [CrossRef]

30. Belmonte, A.; Lama, G.C.; Gentile, G.; Cerruti, P.; Ambrogi, V.; Fernández-Francos, X.; De la Flor, S. Thermally-triggered free-standing shape-memory actuators. Eur. Polym. J. 2017, 97, 241-252. [CrossRef]

31. Belmonte, A.; Lama, G.C.; Cerruti, P.; Ambrogi, V.; Fernández-Francos, X.; De la Flor, S. Motion control in free-standing shape-memory actuators. Smart Mater. Struct. 2018, 27, 075013. [CrossRef]

32. Ciminello, M.; Bettini, P.; Ameduri, S.; Sala, G.; Concilio, A. Monito-Ring: An original fiber optic system for morphing applications. J. Intell. Mater. Syst. Struct. 2015, 26, 2463-2476. [CrossRef]

33. Ciminello, M.; Concilio, A.; Galasso, B.; Richiello, C.; Fabbi, G.; Mataloni, A.; Perugini, P. Sensitivity analysis of OFDR-based distributed sensing for flaws detection in representative coupon from filament wound motor vessel. In Proceedings of the SPIE Commercial + Scientific Sensing and Imaging + Fiber Optic Sensors and Applications XV, Orlando, FL, USA, 14 May 2018. 